\title{
An obituary: complacency claims the life of a model tobacco control programme
}

The highly regarded tobacco control programme within the Minnesota Department of Health $(\mathrm{MDH})$ recently passed away at the tender age of 8 years. The cause of death was listed as a shortfall in the state's budget, but closer examination reveals that complacency was the real cause of death.

Lessons learned from the demise of the tobacco control programme in Minnesota should be carefully heeded by tobacco control advocates elsewhere. The message from Minnesota is clear-no matter how successful a public health programme may be perceived to be, one cannot afford to become complacent.

For the past decade, tobacco control advocates throughout the world have looked with envy and admiration at the accomplishments of the Minnesota campaign against tobacco. In the cover essay in this issue of Tobacco Control, Harty describes the anti-tobacco media campaigns which were the heart of the MDH's tobacco control initiative. ${ }^{1}$

The genesis of the $\mathrm{MDH}$ programme dates back to 1983, when a small group of dedicated health professionals, led by Health Commissioner Sister Mary Madonna Ashton, began work on a comprehensive statewide tobacco control plan. The plan, released in 1984, included 39 separate recommendations. Seven of these recommendations became pieces of legislation and six were enacted into law. One provision of the law required that, beginning in 1985, approximately half a cent from the state's cigarette excise tax be earmarked to fund a tobacco control programme. In 1986, Minnesota became the first state to launch an anti-tobacco media campaign utilising paid advertising. The anti-tobacco campaigns were well received by the public, making tobacco control one of the most visible and popular programmes within the health department. Between 1985 and 1989, the adult smoking rate in Minnesota dropped from $29 \%$ to $21 \%$. Public health officials and politicians declared the tobacco control programme a huge success.

In 1989, citing budget problems and the declining rate of smoking in Minnesota, the governor diverted just under a third of the resources from the tobacco control account to other parts of the state budget. He also ended the earmarking of cigarette excise tax revenues for tobacco control. These budgetary changes were made with little fanfare and few objections from tobacco control supporters. Complacency had set in, and the programme's demise had begun.

Unfortunately, most of those concerned with tobacco control activities in Minnesota did not realise the implications of the governor's actions. In fact, 1989 was the same year that the MDH introduced the famous "Animals" TV spot, its most successful campaign yet. Between 1990 and 1992 , the legislature continued to divert funds away from tobacco control to other parts of the state budget. The retirement of Sister Mary Madonna Ashton as Health Commissioner in 1992 spelled an end to the MDH antismoking programme. In 1993, the legislature all but killed the programme by eliminating funding for the advertising campaign. What just five years before had been hailed as a model public health programme to be emulated by other states, was now reduced to a staff of two persons and an annual budget of $\$ 54000$.

Some may argue that the $\mathrm{MDH}$ tobacco control programme is not dead and is doing well. Three years ago, the MDH was one of 17 states awarded a contract by the National Cancer Institute as part of its American Stop Smoking Intervention Study (ASSIST). The ASSIST contract provides the $\mathrm{MDH}$ with over $\$ 1$ million annually for tobacco control activities. However, ASSIST will only provide resources for five years and there are severe restrictions on how money can be spent. For example, ASSIST funds cannot be used to support the type of media campaign for which the $\mathrm{MDH}$ had become so well known. In Minnesota, availability of ASSIST funds was used as justification for diverting state resources away from tobacco control. Ironically, one of the objectives of the ASSIST project is to help the states establish tobacco control programmes similar to what once existed in the $\mathrm{MDH}$.

What are the lessons to be learned from Minnesota? The political influence of the tobacco industry, present before the $\mathrm{MDH}$ programme began and still present today, had little to do with the demise of the tobacco control programme. What happened in Minnesota is perhaps more dangerous than the tobacco industry's political connections. In Minnesota, tobacco control advocates got lazy. Supporters of the programme allowed the legislature to whittle away at the budget with hardly a whimper. When Sister Mary Madonna Ashton retired from the state health department, there was no one left in high places to fight for the programme, and those hungry for its resources moved in for the kill.

The experience in Minnesota demonstrates that the tobacco control movement cannot afford to rest on its laurels. While momentum for tobacco control has accelerated over the past decade, the battle is far from won. As Yogi Berra once said, "It ain't over till it's over".

Roswell Park Cancer Institute, K MICHAEL CUMMINGS Department of Cancer Control and Epidemiology, Carlton and Elm Streets, Buffalo, New York, USA

1 Harty KC. Animals and butts: Minnesota's media campaign against tobacco. Tobacco Control 1993; 2: 271-4. 